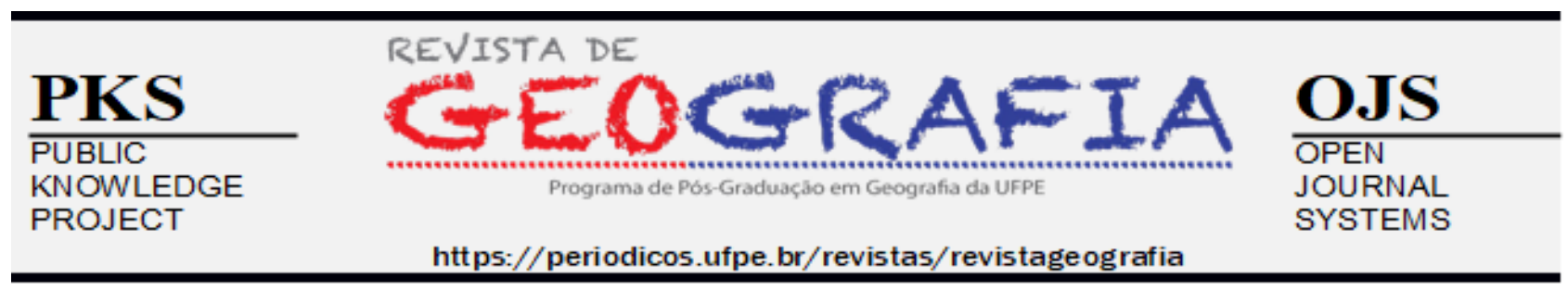

\title{
ESPAÇO GEOGRÁFICO, COVID-19 E EDUCAÇÃO: DISCIPLINAMENTO PELO DISTANCIAMENTO SOCIAL EM SANTA CRUZ DO SUL-RS
}

\author{
Silvia Leticia Carvalho Corrêa ${ }^{1}$, Camilo Darsie $^{2}$
}

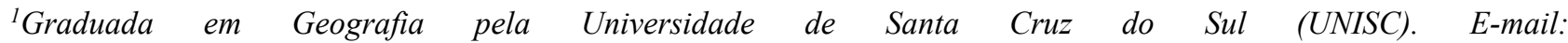
leticia.correa.carvalho@hotmail.com; ORCID: http://orcid.org/0000-0003-4617-0753

${ }^{2}$ Professor e pesquisador do Programa de Pós-graduação em Educação (PPGEdu) e dos cursos de Geografia e Medicina da Universidade de Santa Cruz do Sul (UNISC). E-mail: camilodarsie@unisc.br; ORCID: http://orcid.org/0000-00034696-000X
\end{abstract}

Artigo recebido em 28/05/2021 e aceito em 12/07/2021

\section{RESUMO}

Em decorrência da pandemia de Covid-19, viveu-se em tempos de distanciamento e/ou isolamento social. As questões referentes ao enfrentamento da doença dão ênfase ao espaço e às estratégias de controle de circulação de pessoas. O artigo tem como objetivo problematizar medidas de controle espacial no município de Santa Cruz do Sul, no Rio Grande do Sul, apoiando nos conceitos de poder disciplinador e sanção normativa de Michel Foucault. Não se pretende desenvolver uma discussão moral sobre normas sanitárias, mas destacar suas dinâmicas de produção de sujeitos. Assim, discute-se o Estado e o exercício do poder-saber no enfrentamento da pandemia. Para tanto, são analisados Decretos municipais que estabelecem medidas de enfretamento a pandemia da Covid-19, no município. Como resultados observa-se que os decretos municipais, atuando de forma a disciplinar, normalizar, ordenar e organizar o espaço, por meio de normas, regras e leis a serem cumpridas por cada indivíduo em prol de toda a sociedade, educam e produzem sujeitos aliados aos discursos da saúde.

Palavras-chave: Covid-19; Educação; Espaço; Disciplina

\section{GEOGRAPHY SPACE, COVID-19 AND EDUCATION: DISCIPLINATION FOR SOCIAL DISTANCE IN SANTA CRUZ DO SUL-RS}

\section{ABSTRACT}

As a result of the COVID-19 pandemic, people's lived in times of distancing and/or social isolation. The issues related to react of to the disease emphasize the space and strategies for controlling the circulation of people. The article aims to problematize spatial control measures in Santa Cruz do Sul city, in Rio Grande do Sul, supported by Michel Foucault's concepts of disciplinary power and regulatory sanction. There's no intention 
of developing a moral discussion about health norms, but to highlight their dynamics of subject production. Thus, the State and the exercise of power-knowledge in the face of the pandemic are discussed. To this end, decrees that establish measures to deal with the pandemic of COVID-19 in the municipality are analyzed as well. As a result, it is observed that the decrees, acting in a way to discipline, normalize, order and organize the space, by means of norms, rules and laws to be complied with by each individual for the benefit of the whole society, educate and produce allied subjects to health discourses.

Keywords: COVID-19; Education; Space; Discipline.

\section{INTRODUÇÃO}

Há muitos anos, Yves Lacoste (1988) chamou a atenção para o fato de que a Geografia já foi considerada uma disciplina escolar baseada na memorização de conteúdos e, portanto, reconhecida por muitos, como simplória e enfadonha. Para o geógrafo francês, tal situação ocorria em função da necessidade de resguardo dos conhecimentos geográficos mais apurados, já que estes eram (e ainda são) centrais para as estratégias militares.

Contudo, no período que se sucedeu, muitas mudanças ocorreram no âmbito desta Ciência - desde a perspectiva das pesquisas até os conhecimentos que envolvem diversas práticas pedagógicas. A Geografia contemporânea e sua multiplicidade teórica e metodológica permitem ir muito além da velha visão simplista tensionada por Lacoste e, por isso, ocasiona a aproximação de diferentes áreas do saber como, por exemplo, a Saúde e a Educação. Nesta direção, para além das salas de aula, as ações e discursos que envolvem o espaço, objeto de estudo da Geografia, operam em diferentes sentidos, transformando modos de ser e de estar no mundo por meio de processos educativos.

Neste contexto, em decorrência da pandemia de Covid-19, vive-se em tempos de incertezas marcadas pelos possíveis desdobramentos da doença e pelo distanciamento e/ou isolamento social. Assim, as questões referentes ao enfrentamento da pandemia enfatizam a centralidade do espaço por meio de estratégias de controle de deslocamentos e agrupamentos - por meio dos comportamentos individuais e coletivos que precisam ser repensados. Portanto, tais questões educam sujeitos e populações, em diferentes escalas, acerca dos melhores modos de contenção da doença, a partir de suas relações com o espaço e das dinâmicas de deslocamento e aglomeração.

Por meio da intersecção das áreas da Geografia, da Saúde e da Educação, são problematizadas as medidas de controle e educação espacial, desenvolvidas no município de Santa Cruz do Sul, a partir das teorizações acerca da disciplina e da sanção normativa de Michel Foucault. Para tanto, são tomados como elementos de análise Decretos Municipais que estabeleceram/estabelecem medidas de enfretamento a pandemia no município. Destaca-se, em tempo, que a cidade se localiza no Vale do Rio Pardo, na região central do Rio Grande do Sul, à 155Km da Capital Porto Alegre. Ela possui uma população estimada de 129.427 habitantes, sendo o décimo quinto município mais populoso e quinta economia do Estado.

O objetivo desta manobra é demonstrar como os sujeitos são docilizadas por discursos relativos ao enfrentamento da pandemia e como o espaço emerge como elemento central nas práticas de disciplinamento e nas sanções normativas que produzem sujeitos neste contexto popularmente chamado de "novo normal". Ressalta-se que não se almeja o desenvolvimento de uma discussão moral sobre os efeitos de tais práticas, mas, para além disso, o foco se encontra na problematização das normas de controle sanitário e seus efeitos produtivos que consideramos, aqui, educativos, especialmente na perspectiva da educação em saúde. 


\section{GEOGRAFIA, SAÚDE E EDUCAÇÃO}

Temas relacionados ao campo da Saúde têm se tornado cada vez mais interessantes, relevantes e direcionados para as áreas da Geografia e da Educação. Uma das razões para que isto aconteça é a estreita relação entre o processo saúde/doença e as dinâmicas espaciais e comportamentais. Tais questões podem ser observadas e tensionadas por meio de diferentes conceitos operacionais geográficos como território, ambiente, paisagem, região (SUERTEGARAY, 2001) e, também, a partir de um entendimento que destaca o espaço enquanto fenômeno central que oportuniza a vida e as questões que a envolvem por meio de dinâmicas que aproximam diferentes pontos do globo e, consequentemente, condições de saúde diversas (DARSIE, 2020; MASSEY, 2012; BRAUN, 2008).

As problemáticas relativas à saúde promovem preocupações associadas aos modos e às condições de vida individuais e coletivas que podem ser fortalecidas por meio de práticas educativas, no contexto daquilo que se entende por educação em saúde. A educação em saúde é uma prática de grande relevância no campo da Saúde, especialmente para a saúde coletiva, "uma vez que pode ser considerada no âmbito de práticas onde se realizam ações em diferentes organizações e instituições por diversos agentes dentro e fora do espaço convencionalmente reconhecido como setor saúde". A educação em saúde considera as especificidades, conhecimentos e demandas de diferentes grupos sociais, buscando promover o empoderamento da populações por meio de suas diferentes demandas em saúde. (FALKENBERG et al., 2014 p. 849).

Assim, os debates sobre saúde objetivam fortalecer pessoas em níveis físico e mental, por meio da promoção de comportamentos considerados mais positivos, da qualidade de vida e do empoderamento das populações e comunidades. Complementarmente, ao se atentar os processos de doença, as discussões se voltam principalmente ao controle, enfrentamento e tratamento de problemas já estabelecidos. Diante disto, os saberes geográficos relacionados às condições ambientais, às desigualdades regionais e/ou territoriais, às conexões espaciais, entre outros elementos se tornaram estratégicos (SATURNINO et al., 2019).

Neste contexto, é importante que se considere diferentes escalas para que seja possível se estabelecer relações entre dimensões sociais, econômicas, culturais e educacionais que ocorrem em diferentes níveis e localizações, interferindo em aspectos sanitários (GUIMARÃES, 2015a, 2015b). Destacam-se, por exemplo, preocupações relativas à saúde e às doenças em nível global, tendo em conta que as dinâmicas humanas deslocam estruturas e índices de saúde por diferentes continentes, colocando em contato diferentes realidades locais. Tal situação se deve ao fato de os processos globalizantes terem aumentado o número de viagens internacionais, interestaduais e intermunicipais, colocando em contato diferentes pessoas. Nesses casos, as investigações e argumentos que associam o controle de doenças ao espaço apontam para as redes que interligam vírus e bactérias em diferentes cidades do mundo, por meio de um complexo jogo polirrítmico de movimentos, escalas e condições sanitárias (CRADDOCK; BROWN, 2019; SOUZA, 2014; JACKSON; HENRY, 2017)

Essa relação entre cidades e aspectos sanitários não é nova, pois o antigo pensamento médico considerava o ambiente urbano enquanto um agravante à saúde. Nas primeiras décadas do século XX, foi Max Sorre, na França, quem mais aproximou as pesquisas geográficas à perspectiva da saúde. O geógrafo francês argumentava que a constituição e disseminação de doenças dependiam dos costumes humanos, entre eles aqueles ligados ao vestuário, alimentação, trabalho, condições de moradia e conhecimentos sanitários (GUIMARÃES, 2015b). Assim, era nos centros urbanos que se localizavam os principais organismos de disseminação de doenças, tendo em vista que agrupam bolsões de pobreza. Apesar de Sorre se apoiar em um modelo ecológico, no qual a natureza e biologia se 
sobrepõem às dinâmicas sociais, destaca-se que suas investidas aproximaram diferentes campos do saber (FERREIRA, 1991).

Atualmente, reconhece-se que por meio da articulação das esferas natureza e sociedade, de modo equilibrado, os alastramentos e surtos de doenças podem ser controlados de forma mais eficiente. É a partir da observação e do manejo acerca de diferentes populações, que vivem em diferentes condições ambientais, que podem ser amenizados ou potencializados os efeitos de velhas e novas doenças. Conforme indicam Bernardes, Arruzo e Monteiro (2020), as desigualdades sociais que caracterizam diversos territórios intensificam os agravos causados por doenças.

Ressalta-se, portanto, que, em um mundo marcado pelo desiquilíbrio dos benefícios da globalização, os problemas locais se tornam globais e estes podem atingir drasticamente alguns lugares ao mesmo tempo em que podem passar despercebidos em outros. O processo de globalização é seletivo e tem impacto direto na produção do espaço, provocando intensas mudanças nas relações entre as cidades, acentuando as desigualdades principalmente nos lugares mais pobres. São estes lugares, em que muitos recursos não chegam, que sofrem com as dificuldades, as carências e a falta de recursos médicos hospitalares e educacionais (SANTOS, 2000).

Neste sentido, as cidades de diferentes tamanhos e fluxos populacionais, em momentos de crise, tornam-se foco de preocupações, já que se conectam à rede global de deslocamentos e compartilhamento de doenças, mas nem sempre apresentam condições técnicas, materiais e operacionais de enfrentarem crises sanitárias. Emerge, portanto, outro ponto de interesse da aproximação entre a Geografia e a Saúde: os serviços de saúde nos centros urbanos. É nas maiores cidades que se encontram, no Brasil, boa parte dos serviços de saúde, principalmente os de maior complexidade. Em função disto, o número de pessoas que circulam nas proximidades destes serviços é maior, fato que potencializa o surgimento de outras atividades como, por exemplo, organização de transportes públicos, serviços de alimentação, comércio e etc.., intensificando a circulação de pessoas, animais e produtos (GUIMARÃES, 2015b).

Diante destas questões, o tensionamento das dinâmicas urbanas, levando-se em conta as demandas de saúde, pode ser revelador e, certamente, se constitui enquanto uma importante prática de promoção da saúde e de controle de doenças por meio de ações educativas. Dadas as desigualdades estruturais de muitas regiões, tais dinâmicas revelam que conforme maior a oferta de serviços de saúde, maiores a quantidade e a circulação de pessoas e, portanto, maior o número de vetores para doenças diversas. Assim, mesmo que se intente ajustar as estruturas de atendimento, tornando-as maiores e mais disponíveis, os riscos de adoecimento tornam-se igualmente maiores caso não hajam medidas de educação e empoderamento das populações.

\section{A ORIGEM DA COVID-19 E SUA DISSEMINAÇÃO}

A Covid-19 é a doença causada pelo SARS-CoV-2, ou seja, um novo tipo de Coronavírus. Estes vírus - Coronavírus - pertencem a uma mesma família e podem circular tanto entre pessoas quanto entre animais, causando problemas respiratórios. De acordo com a Fundação Oswaldo Cruz, a origem genética do Coronavírus que causa a Covid-19 ainda é desconhecida. No entanto, logo foi descoberto que o SARS-CoV-2 começou a infectar pessoas em um grande mercado de frutos do mar, na cidade de Wuhan, na China. Partindo disto, em alguns meses, contabilizaram-se milhões de notificações de casos de infecções e óbitos, em quase todo o mundo (PORTAL FIOCRUZ, 2020).

Primeiramente, os problemas recaíram sobre os países vizinhos da China, cujas relações sociais e comerciais com o país são mais frequentes. Em 20 de janeiro de 2020, a Coreia do Sul registrou o primeiro caso e, no dia seguinte, Taiwan, Japão, Hong Kong e Singapura também foram afetados. Como o vírus não poderia ficar apenas na Ásia, devido a suas inúmeras relações com outros 
continentes, logo chegou na Europa, mais precisamente no norte da Itália, seguindo para a França e, depois, por todo o continente europeu (DUMONT, 2020).

O primeiro caso confirmado da doença nos Estados Unidos da América, notificado pelo Centro para Controle Prevenção de Doenças (CDC), ocorreu no dia 21 de janeiro. A vítima foi um homem de aproximadamente 30 anos que havia voltado da China na semana anterior ao diagnóstico. No Brasil, o Ministério da Saúde (2020) confirmou que o primeiro caso de Covid-19 foi notificado em 26 de fevereiro de 2020, em São Paulo. Após 17 dias, o número de notificações brasileiras indicava 100 casos e, em mais 7 dias, era registrado o milésimo caso. Partindo deste, em 14 dias, atingiu-se a marca de 10.000 casos.

Em abril de 2020, o Brasil vivenciou o processo de interiorização da pandemia. A disseminação não ocorreu de forma homogênea, pois os municípios próximos aos grandes centros já apresentavam casos da doença. Como exemplos, podem ser citadas cidades como Rio de Janeiro, São Paulo, Belo Horizonte, Porto Alegre, Fortaleza, Salvador, Brasília e Manaus. (PORTAL FIOCRUZ, 2020). Diante destas informações percebe-se que a pandemia de Covid-19, deixou em evidência problemas que existem no Brasil, há muitos anos, como por exemplo hospitais com déficit de leitos, de equipamentos e de profissionais de saúde, problemas de infraestrutura, saneamento básico e moradias precárias, o que nos leva a evidenciar determinantes sociais diferentes para cada estado.

No Rio Grande do Sul, conforme dados registrados pela Secretária Estadual da Saúde (2020), o primeiro caso foi notificado em 10 de março de 2020. Nesta mesma data foram notificados 190 casos suspeitos no Estado. Em abril de 2020, o Portal ObservaDR/Covid-19 (2020) apresentou dados evidenciando que a doença havia adentrado o território gaúcho a partir da capital Porto Alegre e região metropolitana, espalhando-se pelo interior do estado.

Conforme divulgado pelo Portal GeoSaúde (2020), site de monitoramento organizado pela Universidade de Santa Cruz do Sul, o estado do Rio Grande do Sul atingiu a marca de 388 mil casos, durante o ano de 2020 (MARTINI; DARSIE, 2020a). No município de Santa Cruz do Sul, conforme noticiado pela Gazeta do Povo (2020), principal jornal da cidade, o primeiro caso de Covid-19 foi um homem de 48 anos, confirmado em 5 de abril de 2020. Logo após a divulgação deste primeiro caso, novas notificações foram divulgadas e, de um modo geral, observou-se aumento do número de casos de Covid-19, em diferentes níveis de crescimento, em todos os bairros do município (OBSERVADR/COVID-19, 2020). Até meados de dezembro de 2020, o total de casos no município de Santa Cruz do Sul atingiu a marca de 3,5 mil casos (MARTINI; DARSIE, 2020b).

Devido à chegada e à dispersão espacial do vírus da Covid-19, no município de Santa Cruz do Sul, foram aplicados Decretos municipais estabelecidos para o enfrentamento da pandemia. Tais decretos buscavam estabelecer limitações relativas aos deslocamentos pela cidade e, para além disso, promover maior conscientização da população conforme preveem as estratégias de educação em saúde.

\section{PERCURSO METODOLÓGICO}

As reflexões apresentadas aqui se configuram por meio do viés pós-estruturalista. Entendese que a partir desta perspectiva é possível se desconstruir conceitos e articular diferentes áreas do conhecimento como a Geografia, a Saúde e a Educação. O pós-estruturalismo é entendido como um modo de pensar, de escrever, de filosofar e não como uma metodologia dura ou como um conjunto de técnicas estruturadas e homogêneas (PETERS, 2000). Assim, o pós-estruturalismo se constitui a partir da diversificação de muitos teóricos.

Entretanto, o pós-estruturalismo não pode ser simplesmente reduzido a um conjunto de pressupostos compartilhados, a um método, a uma teoria, ou até mesmo a uma escola. É melhor referir-se a ele com um movimento do pensamento - uma complexa rede de 
pensamento - que corporifica diferentes formas de práticas crítica. O pós-estruturalismo, é decididamente, interdisciplinar, apresentando-se por muitas e diferentes correntes (PETTERS, 2000, p. 29).

De acordo com Aguilar e Gonçalves (2017), o pós-estruturalismo opera com a desconstrução de conceitos que são considerados verdades absolutas e centrais em diferentes disciplinas. Partindo do princípio de seja um guarda-chuva que abrange as mais diferentes teorias e perspectivas, pode-se levantar uma falsa ideia de tal caminho de pesquisa seja desorganizado, mas não é, pois segue balizas teóricas condizentes com as discussões que lhe envolvem. Assim, nesta pesquisa, utiliza-se do tensionamento das relações de poder articuladas à Covid-19, ao controle espacial e à educação.

Foucault explica que as relações de poder, estão presentes em todas as sociedades desde a antiguidade até os dias atuais. Segundo Barros (2019), o poder, para Foucault, não é algo totalmente negativo é preciso um olhar positivo para o poder, vê-lo como sendo algo produtivo e transformador.

Temos que deixar de descrever sempre os efeitos do poder em termos negativos: ele exclui, ele reprime, ele recalca, ele censura, ele abstrai, ele mascara, ele esconde. $\mathrm{Na}$ verdade, o poder produz; ele produz realidade; produz campos de objetos e rituais da verdade. (FOUCAULT, 2009, p. 161).

É adequado, portanto, pensar que a ideia de "poder" (como se fosse um objeto) seja substituída pela noção de "relações de poder" (FOUCAULT, 2011). Furtado e Camilo (2016) afirmam que, para Foucault, as relações de poder operam de modo difuso, capilar, espalhando-se por uma rede social que inclui instituições diversas como a família, a escola, o hospital, a clínica. Elas são consideradas, um conjunto de relações de forças múltiplas, produzindo os sujeitos sobre quem operam e sobre quem falam. Tais relações de força são móveis e suscetíveis de se modificarem, compondo arranjos transitórios dados a uma constante modificação. Conforme Santos e Nascimento (2014) as relações de poder permitem conceituar e contextualizar as direções políticas e sociais na atualidade. A partir dessa visão é possível refletir sobre os aspectos positivos que envolvem relações poder e o risco de discursos de dominação onde rompem o limite da ética.

As relações de poder se encontram, sempre, associadas a alguma forma de saber. Para se exercer o poder, por meio de relações, é necessário conhecimento e saberes que servem de ferramentas e pretexto para sua execução. Em nome da verdade, validam e viabilizam práticas autoritárias de segregação, monitoramento, gestão dos corpos e do desejo (SANTOS e NASCIMENTO, 2014).

Assim, problematiza-se os decretos municipais que apresentam as questões referentes ao distanciamento social, frente a pandemia de Covid-19, no município de Santa Cruz do Sul (2020). Partindo disso, podem ser tensionadas as formas como os corpos são docilizados pelos discursos de verdade, como o Estado exerce seu poder-saber no enfrentamento da pandemia, como essas tensões moldam e subjetivam sujeitos e como o espaço emerge como elemento central de disciplinamento e educação. De certo modo, tais práticas dão início a novos modos de pensar as relações sociais e espaciais que, em outros momentos, servirão de base epistemológica para ações de educação em saúde.

Portanto, com base nos estudos foucaultianos sobre o poder disciplinador e a sanção normativa, enquanto ferramentas de análise, é possível problematizar e discutir os Decretos municipais da cidade de Santa Cruz do Sul como um conjunto de ferramentas modernas e técnicas de disciplinamento e controle espacial diante a pandemia da Covid-19. A disciplina opera como uma ferramenta reguladora dos indivíduos. Por disciplina entende-se:

Métodos que permitem o controle minucioso das operações do corpo, que realizam a sujeição constante de suas forças e lhes impõem uma relação de docilidade-utilidade, são o que 
podemos chamar as "disciplinas". Muitos processos disciplinares existiam há muito tempo: nos conventos, nos exércitos, nas oficinas também (FOUCAULT, 2009, p. 133).

Os Decretos municipais atuam no sentido de disciplinar, normalizar, ordenar e organizar o espaço, por meio de normas, regras e leis a serem cumpridas por cada sujeito em prol de toda a sociedade. A disciplina gera uma conformidade, o decreto opera sobre os indivíduos um poder disciplinador que resulta na obediência frente às regras estabelecidas e, consequentemente, faz emergir novas formas de ser e estar no espaço.

Em relação ao poder disciplinar, diante do enfraquecimento gradativo do poder soberano, há uma necessidade de remanejar o poder de punir, que deixa de ser exclusivamente exercido pelo soberano e passa a ser repartido por diversas esferas da sociedade. Fazer da punição e da repressão das ilegalidades uma função regular, coextensiva à sociedade permite não punir menos, mas punir melhor; punir talvez com uma severidade atenuada, mas para punir com universalidade e necessidade; inserir mais profundamente no corpo social o poder de punir (SILVA, 1997).

Diante disso, outro instrumento de poder é a sanção normativa ou a punição. Para Barros (2019), o julgamento dos indivíduos opera através da norma que é um padrão de comportamento estabelecido pela sociedade. Aquele indivíduo que não cumpre, tanto normas quanto regras, precisa ser punido. A norma se estabelece como figura do normal sendo o princípio de coerção para quem é considerado anormal. Os Decretos municipais também operam de maneira coercitiva, pois aqueles que não os cumprem, são punidos por meio de multa ou de interdição.

Pode-se entender, portanto, que os Decretos municipais de Santa Cruz do Sul (2020), por serem instrumentos disciplinadores, no contexto da pandemia de Covid-19, são responsáveis pelo controle do espaço por meio de medidas que prezam a saúde e a vida, a partir de ações que podem ser considerados educativas. Não se pretende, aqui, desenvolver uma discussão moral sobre a disciplina, a sanção normativa e o Decretos, mas, em outra direção, tensionar tal relação enquanto um processo que produz, enquanto educa, sujeitos.

A partir do dia 11 de maio de 2020 passou a valer, em todo território gaúcho, um novo modelo de enfrentamento da Covid-19, chamado de Distanciamento Controlado, estabelecido por meio do Decreto 55240. De acordo com o Governo do Estado do Rio Grande do Sul, o modelo de Distanciamento Controlado do Estado foi construído com base em critérios de saúde e de atividades econômicas. Criou-se um sistema de bandeiras, com protocolos obrigatórios e critérios específicos a serem seguidos pelos diferentes setores econômicos. O estado foi dividido em 20 regiões que eram analisadas considerando a velocidade de propagação da doença e a capacidade de atendimento do sistema de saúde. No total, foram utilizados 11 indicadores como, por exemplo, número de novos casos, óbitos e leitos de UTI disponíveis. Tais indicadores determinaram a classificação das bandeiras de cada região, em cada período de avaliação. (SECRETARIA DE SAÚDE DO ESTADO DO RIO GRANDE DO SUL, 2020).

Conforme o grau de risco em saúde, cada região recebia uma bandeira nas cores amarela, laranja, vermelha ou preta. $\mathrm{O}$ monitoramento era feito semanalmente e a divulgação das bandeiras ocorria aos sábados, com validade a partir da segunda-feira seguinte. Os protocolos obrigatórios deveriam ser respeitados em todas as bandeiras. Além disso, cada setor econômico teve critérios específicos que variavam de acordo com a bandeira. Para além do sistema de bandeiras de distanciamento controlado do RS, o município de Santa Cruz do Sul estabeleceu uma série de decretos municipais a fim de estabelecer medidas de enfrentamento da pandemia .

Diante do exposto, o método utilizado para a discussão foi a análise documental, a partir dos Decretos municipais oficializados durante a pandemia de Covid-19, no município. Os principais decretos analisados são o Decreto10.565 de 19 de março de 2020, que declara situação de calamidade, o Decreto 10.621 de 17 de maio de 2020, que reitera calamidade pública, o Decreto 10.683 de 24 de 
julho de 2020, referente a medidas coercitivas de aglomerações e o Decreto 10.719 de 25 de setembro de 2020 que dispõe sobre a cogestão municipal do distanciamento social controlado do Rio Grande do Sul (SANTA CRUZ DO SUL, 2020).

No entanto, a complexidade que envolve a adesão a essas medidas é grande, podendo muitas vezes estar relacionada a fatores como o comportamento humano, incluindo falsas percepções de um risco invisível, subestimação da responsabilidade individual e falta de conhecimento, atitudes que podem interferir na adesão às medidas de prevenção. Embora muitos sujeitos relatem a importância e a adesão às medidas de prevenção da doença, há diversas comunidades onde esgoto e água encanada ainda não são uma realidade e, portanto, práticas de higiene e prevenção são prejudicadas. Ainda ocorrem outras questões típicas do contexto capitalista que podem influenciar nestas medidas, como as de cunho econômico, político, entre outras.

\section{DISCIPLINAMENTO PELO DISTÂNCIAMENTO SOCIAL EM SANTA CRUZ DO SUL}

A Organização Mundial da Saúde declarou que a disseminação da Covid-19 caracteriza-se como uma pandemia no dia 11 de março de 2020, quando lançou um comunicado oficial. Partindo disto, instituiu as medidas para a prevenção e enfrentamento da doença a serem adotadas globalmente, especialmente pelos países membros. Tais medidas incluem cuidados com o corpo, com a higienização das mãos, com o toque em mucosas e com a proteção das pessoas ao redor, ao espirrar ou tossir, com uso de máscaras ou lenços descartáveis. Em se tratando de profissionais de saúde, tais equipamentos de segurança se tornaram obrigatórios no atendimento de pacientes suspeitos ou infectados (OLIVEIRA; LUCAS; IQUIAPAZA, 2020).

Além disso, foram indicadas precauções ligadas às possibilidades de deslocamentos e organização espacial: o distanciamento social, a não formação de aglomerações e isolamento social acompanhado da utilização de máscaras em casos de quadros gripais e infecções causadas pela doença (OMS, 2020). Neste contexto, alguns termos passaram a ser usados para distinguir ações de controle de infeções, torando-se comuns em diferentes comunicações oficiais e conversas diversas. Destacamse a quarentena, o isolamento social e o distanciamento social. Esses termos dizem respeito a medidas de saúde pública não farmacológicas, principalmente na ausência de vacinas e medicamentos efetivos.

As primeiras discussões sobre quarentena emergiram a partir de 1851, porém, as primeiras recomendações oficiais para a implementação de quarentenas ocorreram na primeira Assembleia Mundial de Saúde, da ONU, em 1948. Na ocasião foi criado um Comitê de Especialistas em Epidemiologia e Quarentena Internacional (GARRIDO; GARRIDO, 2020). Segundo Aquino et al (2020), a quarentena é a restrição do movimento de pessoas expostas a uma doença contagiosa, mas que não estão doentes, porque não foram infectadas ou porque ainda estão no período de incubação. Pode ser no nível individual ou de grupo, mantendo as pessoas nos próprios domicílios, em instituições ou outros locais previamente estabelecidos. A quarentena pode ser voluntária ou obrigatória.

O isolamento social deve entendido como separação. Nessa medida, as pessoas contaminadas com alguma doença contagiosa são separadas das não infectadas (GOLDIN, 2020). Já o distanciamento social ou contenção social tem como objetivo reduzir a interação de grupos maiores, por meio do fechamento de escolas, escritórios, entre outros. Quando preciso, pode-se aumentar os limites de restrição de entrada e saída de bairros, municípios, estados e países (GARRIDO; GARRIDO, 2020). O distanciamento social é uma das medidas utilizadas no combate a pandemias que têm como objetivo reduzir o contato entre pessoas em uma comunidade, incluindo pessoas infectadas que ainda não tenham sido identificadas. Como as doenças transmitidas por gotículas 
respiratórias exigem certa proximidade física para causarem o contágio, o distanciamento social permite reduzir a transmissão (AQUINO et al, 2020).

Partindo destas questões, o Decreto 10.565, de 19 de março de 2020, deu início às medidas de controle da pandemia de Covid-19 no município de Santa Cruz do Sul, por meio da vigilância espacial, tendo em conta as ações comentadas. Ele inaugurou o que pode ser entendido como uma disciplina espacial e relacional, pois seu objetivo foi modelar as condutas de indivíduos, ajustandoos e corrigindo-os ao mesmo tempo em que passou a incentivar ações desejáveis tais como cuidados em saúde, "paciência e principalmente resiliência" (SANTA CRUZ DO SUL, 2020, p. s/n). Em seu primeiro artigo, o documento decreta a situação de calamidade pública no Município, instituindo que, enquanto perdurar tal situação de doença, são obrigatórias as medidas excepcionais previstas. Em seu artigo quarto, determina o fechamento dos estabelecimentos comerciais, industriais e de prestação de serviços não essenciais (SANTA CRUZ DO SUL, 2020). Essa medidas de fechamento e de cancelamento do funcionamento dos estabelecimentos públicos agem por meio da ideia de ordenamento do espaço e dos sujeitos.

Já o Decreto 10.621, de 17 de maio de 2020, reitera a calamidade pública, dispondo das determinações dos decretos estaduais a serem seguidos por todas as regiões do estado do RS. No segundo artigo do documento, as medidas emergenciais determinadas pelo Poder Executivo do Estado do RS dão início à aplicação de medidas sanitárias segmentadas, aplicáveis em todo o território do Município de Santa Cruz do Sul, sem prejuízo das medidas sanitárias de interesse exclusivamente local que vierem a ser determinadas no documento. No terceiro artigo, do mesmo decreto, é mencionado que a "Administração Pública Municipal fiscalizará a observância das medidas emergenciais de contenção e enfrentamento à pandemia" (SANTA CRUZ DO SUL, 2020, s/n). Deste modo, destaca-se a possibilidade de alterações locais, em relação ao manejo das ações disciplinares, de acordo com as demandas do município.

Os decretos operam em duas direções: uma que diz respeito aos novos modos de circular e usufruir do espaço público, especialmente em função das redes formadas por contatos humanos, e outra que trata dos cuidados e condutas pessoais. Neste sentido, o Estado e, em um segundo momento, o município, por meio de suas autoridades políticas e sanitárias, fazem valer um conjunto de conhecimentos científicos e estratégicos que se tornam reguladores de condutas, especialmente ao serem validados por seus divulgadores e aplicadores. De acordo com Santos e Nascimento (2014), conhecimento e saberes para gestão e regulação do espaço são necessários e, por meio deles, decisões são tomadas e divulgadas. Nessa direção, portanto, o decreto produz o distanciamento social enquanto instrumento de disciplina, já que na medida em que os estabelecimentos não essenciais deixam de funcionar, automaticamente, a circulação de pessoas pelos ambientes públicos também diminui - pela inibição -, fazendo com que a propagação espacial da doença seja amenizada. É o controle dos corpos, por meio de um conjunto de enunciados, de normas públicas e de controle espacial que produz novos acordos, limites e controles coletivos. Ao mesmo tempo, sujeitos são subjetivados no sentido de apoiarem as medidas de gerenciamento espacial de acordo com os saberes preponderantes, divulgados e operacionalizados por autoridades consideradas habilitadas.

Certamente, como em quaisquer relações de poder, emergem movimentos e discursos de resistência. Diante disso, da mesma maneira ocorrida em diferentes cidades do Brasil e do mundo, protestos e comportamentos de enfrentamento ao controle dos corpos e à vigilância pública criaram tensões que agiram na direção de relativizar os discursos da saúde. Assim, os processos de produção e educação de sujeitos para o controle da doença, passaram a enfrentar verdadeiros ataques pautados, ironicamente, nos princípios democráticos. Sobre tal questão, é fundamental que seja chamada a atenção para o fato de que cuidados relacionados à vida, pelo viés coletivo, também compõem a ideia de democracia, mesmo que para isso seja necessário o estabelecimento de normas mais duras em determinados momentos de emergência. 
Complementarmente, portanto, outro elemento a ser problematizado como instrumento de poder é a sanção normativa ou punição. Para Barros (2019), o julgamento dos indivíduos opera através das normas que constituem um padrão de comportamento estabelecido pela sociedade e pelas práticas disciplinares. Os indivíduos que não as cumprem, tanto norma quanto regra, precisam ser punidos como maneira de afirma-la. Deste modo, a punição torna-se um dispositivo de educação. A norma se estabelece como figura do normal, sendo o princípio da coerção para quem é considerado anormal. O Decreto 10.683, de 24 de julho de 2020, por exemplo, apresenta os critérios a serem seguidos perante o não cumprimento das normas ou regras de saúde pública.

Nele, ficam instituídas as medidas coercitivas por formação de aglomerações e os procedimentos para a utilização do poder de polícia pela administração pública municipal. Em seu primeiro artigo, fica claro que seu objetivo é combater a pandemia no Município de Santa Cruz do Sul por meio da responsabilização de condutas que infrinjam as normas de saúde pública. Assim, ele age definindo regras a serem observadas quanto ao exercício do poder de polícia pelos agentes da Administração Pública Municipal (SANTA CRUZ DO SUL, 2020).

Para além disso, são tratadas questões referentes ao controle espacial: 1) "Fica vedada a formação de aglomeração em espaços públicos, tais como parças, parques, calçadões, vias públicas e assemelhados, bem como em espaços privados em que sejam realizados festas, eventos e atividades congêneres"; 2) "o poder de polícia administrativo é a possibilidade do município, através de seus agentes de fiscalização e da Guarda Municipal, assegurada a ampla defesa e o contraditório, sancionar pessoas físicas ou jurídicas, que de acordo com a legislação vigente"; 3) comportamentos que furem o distanciamento, "praticados em local público ou privado, realizados na presença de agente públicos ou verificados mediante denuncia, que colocarem em risco a saúde pública, [...], nas sanções relativas as suas infrações; 4) "Infrações cominadas no presente Decreto serão sancionadas com multa e interdição" (SANTA CRUZ DO SUL, 2020, p. s/n).

Com suporte na teoria já apresentada, entende-se que é através da sanção normativa que o poder disciplinar estabelece regras que visam reprimir uma série de comportamentos indevidos como, por exemplo, as aglomerações e o deslocamento dos sujeitos pelo espaço. Isso ocorre por meio de procedimentos punitivos como multas e interdição de estabelecimentos. Contudo, é importante que se lembre que o poder é considerado um conjunto de relações de forças múltiplas, móveis e em constante transformação (FURTADO; CAMILO, 2016). Assim, ele pode ser reorientado por meio das relações estabelecidas em diferentes parcelas espaciais, fazendo com que o decreto em questão, por exemplo, sofra algumas flexibilizações.

Partindo de tal situação, no Decreto 10.719 de 25 de setembro de 2020, que dispõe sobre a cogestão municipal do distanciamento social controlado no estado do Rio Grande do Sul, o Governo do Estado do Rio Grande do Sul permite aos gestores de cada região deliberar sobre aplicação de protocolos menos restritivos que aqueles previstos na bandeira de risco estadual, de cada região. Torna-se possível a flexibilização e a permissão de funcionamento de estabelecimentos que antes eram proibidos de atuar. Como exemplo desta flexibilização, cita-se a retomada dos bufês self-service e a reabertura dos banheiros públicos das praças de Santa Cruz do Sul.

Reitera-se que o poder utiliza-se de forças múltiplas, entre elas as econômicas. É interessante pensar, portanto, que a partir do momento em que o distanciamento social e o fechamento de estabelecimentos comerciais são afetados financeiramente, diferentes tensões emergem para a flexibilização das medidas de enfrentamento da pandemia, possibilitando assim, uma nova dinâmica espacial.

O discurso econômico, principalmente, a parte que se refere ao empreendedorismo e à possibilidade de rearranjo da economia nacional ganhou fôlego, se tornando central para diversas discussões. Tal situação, contrariou, portanto, um modo de pensar que há muito tempo colocava os enunciados da saúde em vantagem quando associados a outras áreas (DARSIE, 2020, p. 2). 
Aqui, vale ser destacado que os Decretos observados, ao serem alterados devido ao jogo de forças, típico das relações multifacetadas do poder, também transformam os modos de pensar que eles mesmos produzem por meio da disciplina. Ao mesmo tempo em que produzem sujeitos moldados pela doença, produzem sujeitos por meio dos discursos econômicos. Talvez, tais lógicas contraditórias, no contexto da pandemia, estejam se tornado complementares, fato que torna bastante complexas as relações educativas estabelecidas pela Covid-19. Os Decretos municipais atuam de forma a disciplinar, normalizar, ordenar e organizar o espaço, por meio de normas, regras e leis a serem cumpridas por cada sujeito em prol de toda a sociedade, seja pelo viés da doença seja pela economia. A disciplina educa sujeitos, gerando uma conformidade e o decreto opera sobre os indivíduos por meio do poder disciplinador que resulta da obediência frente as regras estabelecidas.

No entanto, é importante lembrar que é a partir deste conjunto de ações, que vive-se durante o desenrolar da doença, que emergem - e ainda irão emergir - novas perspectivas que atravessam e atravessarão as práticas de educação em saúde, destacando a relação entre a Geografia, a Saúde e a Educação como um dos eixos marcantes nas discussões acerca do tema.

\section{CONSIDERAÇÕES FINAIS}

No decorrer do ano de 2020, o assunto que esteve em maior evidência foi a pandemia de Covid-19 e os desdobramentos sociais, culturais, econômicos e educacionais ligados a ela. Neste sentido, emergiram diferentes formas de análise e de enfrentamento da disseminação da doença. Estes movimentos geraram, consequentemente, novas rumos relacionados às estratégias de controle sanitário.

A emergência de uma espécie de centralidade do espaço enquanto dimensão reguladora e educadora dos corpos foi um desses modos emergentes de controle. $\mathrm{O}$ espaço deve ser entendido como uma dimensão que molda nossas compreensões acerca da vida ao mesmo tempo em que é moldado por elas. Por meio de suas formas físicas e de suas formas mentais modula nossos entendimentos relacionados ao mundo, nossas atitudes frente aos outros, nossas formas de viver a globalização, nossas maneiras de falar a respeito da urbanização e de darmos sentidos a essas questões, bem como a muitas outras. Assim, é multifacetado e se encontra em constante transformação, em constante ressignificação, pois ele é a dimensão do social que relativiza o tempo e reconfigura as formas naturais e sociais (DARSIE, 2020; SOUZA, 2014; MASSEY, 2012; SILVA, 1997).

Com base no que foi discorrido, torna-se possível pensar a partir da articulação de saberes geográficos, de questões de saúde e das prática educativas, já que o espaço é um fenômeno que oportuniza a vida e os modos de ser dos mais diferentes sujeitos. Tal situação permite a aproximação da concepção de poder proposta por Foucault e, partindo disso, pensar que os Decretos municipais ligados às condutas sociais públicas agem como ferramentas de disciplina e, para tanto, aplicam sanções para aqueles que resistem a ela. Vale a pena ter-se em mente, antes do fim, que as relações de poder que produzem sujeitos não são, necessariamente, negativas, opressoras ou dominadoras. Elas podem ser positivas dependendo dos modos como operam e encontram-se em constante transformação.

\section{REFERÊNCIAS}

AGUILAR, M. A. B.; GONÇALVES, J. P. Conhecendo a perspectiva pós-estruturalista: breve percurso de sua história e propostas. Revista Conhecimento Online, v.1, n. 9, p. 36-44, jan./jun. 2017. Disponível 
$<$ https://periodicos.feevale.br/seer/index.php/revistaconhecimentoonline/article/view/460>. Acesso em: 15 nov. 2020

AQUINO, Estela M. L; et al. Medidas de distanciamento social no controle da pandemia de COVID-19: potenciais impactos e desafios no Brasil. Ciência e Saúde Coletiva, Vol.25. Rio de Janeiro, Jun.2020.

Disponível

em: $<$ https://www.scielo.br/scielo.php?pid=S141381232020006702423\&script=sci_arttext $>$ acesso em: 20 out. 2020.

BARROS, Igor de; A concepção relacional do poder em Foucault e a omissão da valoração ética. Revista Philia/ Filosofia, Literatura \& Arte, Porto Alegre, Vol.1, n 2, p 219-339, Out. 2019.

BERNARDES, Julia Adão; ARRUZZO, Roberta Carvalho; MONTEIRO, Daniel Macedo Lopes Vasques. Geografia e Covid-19: neoliberalismo, vulnerabilidades e luta pela vida. Revista Tamoios, [S.1.], v. 16, n. 1, maio 2020. ISSN 1980-4490. Disponível em: <https://www.epublicacoes.uerj.br/index.php/tamoios/article/view/50645/33481>. Acesso em: 17 nov. 2020. doi:https://doi.org/10.12957/tamoios.2020.50645.

BRAUN, B. Thinking the City through SARS: Bodies, Topologies, Politics. In: Ali H, Keil R. (editors). Networked Disease: Emerging infections in the global city. Oxford: Wiley-Blackwell, 2008

CRADDOCK S., BROWN T. Handbook of Global Urban Health, Routledge, 2019

DARSIE, Camilo. Biopolíticas da Covid-19. Journal of Infection Control, 9, 1. 2020. Disponível em: https://jic-abih.com.br/index.php/jic/article/view/350/pdf. Acesso realizado em: 24 de março.

DARSIE, Camilo; WEBER, Douglas Luís. Doença e controle espacial: questões sobre dispersão e isolamento em tempos de pandemia. Journal infection control. Ano IX. Vol 9, n. 2, abr/jun. 2020.

DUMONT, François-Gérard. Covid-19: fim da geografia da hipermobilidade? Espaço e Economia. [online], 18, 2020. URL:http://journals.openedition.org/espacoeconomia/12926; Acesso em: 27 mai 2020. DOI: https://doi.org/10.4000/espacoeconomia.12926

FALKENBERG, Mirian Benites et al. Educação em saúde e educação na saúde: conceitos e implicações para a saúde coletiva. Ciência \& Saúde Coletiva [online]. 2014, v. 19, n. 03 [Acessado 25 Março 2021], pp. 847-852. Disponível em: <https://doi.org/10.1590/141381232014193.01572013>.

FERREIRA, Marcelo Urbano; Epidemiologia e geografia: o complexo patogênico de Max Sorre. Caderno de Saúde Pública, v7.n.3. Rio de Janeiro. Jul./ set. 1991. Disponível em : https:/www.scielo.br/scielo.php?script=sci_arttext\&pid=S0102-

311X1991000300002\&lng=pt\&tlng=pt . acesso em: 07 set. 2020.

FOUCAULT, Michel. História da Sexualidade: A Vontade de saber. 19. Ed. São Paulo: Graal, 2009.

FOUCAULT, Michel. Microfísica do poder. Rio de Janeiro: Edições Graal, 2011.

FURTADO, R. N; CAMILO, J. A. de Oliveira. O conceito de biopoder no pensamento de Michel Foucault. Rev. Subj., Fortaleza, v. 16, n. 3, p. 34-44, dez. 2016. Disponível em < http://pepsic.bvsalud.org/scielo.php?script=sci_arttext\&pid=S2359-07692016000300003> acesso em 15 nov. 2020. 
GARRIDO, R. G; GARRIDO, F.S.R. Covid-19: um panorama com ênfase em medidas restritivas de contato interpessoal. Interfaces científicas. Aracajú. V8. N. 2. P127- 141. Disponível em: $<$ https://periodicos.set.edu.br/saude/article/view/8640> Acesso em:08 nov. 2020.

GAZETA DO POVO. Primeiro caso de coronavírus nos Estados Unidos Disponível em: https://www.gazetadopovo.com.br/mundo/breves/primeiro-caso-coronavirus-estados-unidos/acesso em: 16 de dez. 2020.

GOLDIM, José Roberto. Covid-19, Quarentena e Confinamento. Disponível em:< https://bioeticacomplexa.blogspot.com/2020/02/>. Acesso em: 08 nov. 2020.

GUIMARÃES, R. B. Geografia da saúde: categorias, conceitos e escalas. In: Saúde: fundamentos de Geografia humana. São Paulo: Editora UNESP, 2015a, pp. 79-97. Disponível em:< http://books.scielo.org/id/4xpyq/pdf/guimaraes-9788568334386-05.pdf $>$ acesso em: 04 jun 2020.

Geografia e saúde. In: Saúde: fundamentos de Geografia humana. São Paulo: Editora UNESP, 2015b, pp. 17-39. Disponível em: <http://books.scielo.org/id/4xpyq/pdf/guimaraes9788568334386-02.pdf> acesso em: 04 jun 2020.

JACKSON, P., HENRY, C. The Needs of the "Other" Global Health: The Case of Remote Area Medical in Global Health and Geographical Imaginaries, Clare Herrick (ed), Routledge, 2017.

LACOSTE, Yves. A geografia - isso serve, em primeiro lugar para fazer guerra. Tradução Maria Cecília França - Campinas, SP: Papirus, 1988.

MASSEY, Doreen. Pelo Espaço: Uma nova política da espacialidade. Tradução de Hilda Pareto Maciel e Rogério Haesbaert. 3. ed. Rio de Janeiro: Bertrand Brasil, 2012.

MINISTÉRIO DA SAÚDE. Painel coronavírus. https://covid.saude.gov.br/, acessado em 28/Abr/2020.

MARTINI, Patrick L.; DARSIE, Camilo. Evolução dos casos de Covid-19 no Rio Grande do Sul: dados públicos SES-RS 2020a. 5 graficos. Disponível em: https://geosaudevrp.org/2020/11/11/evolucao-dos-casos-de-covid-19-no-rio-grande-do-sul-dadospublicos-secretaria-estadual-de-saude-rs/

MARTINI, P. L.; DARSIE, C. Evolução dos casos de Covid-19 no Vale do Rio Pardo: dados públicos SES-RS. 2020b. 5 gráficos. Disponível em: https://geosaudevrp.org/2020/09/30/evolucaodos-casos-de-covid-19-no-vale-do-rio-pardo-dados-publicos-ses-rs/

OBSERVADR/Covid-19. Disponível em: http://observadr.org.br/portal/dados-e-mapas-do-riogrande-do-sul-e-da-regiao-dos-vales/. Acesso em: 18 de dezembro de 2020.

OLIVEIRA, Adriana Cristina de; LUCAS, Thabata Coaglio; IQUIAPAZA, Robert Aldo. O que a pandemia da covid-19 tem nos ensinado sobre adoção de medidas de precaução? Texto contexto. $\begin{array}{lllll}\text { Florianópolis. } & \text { v. } & 29, & 2020 . & \text { Disponível }\end{array}$ $<$ https://www.scielo.br/scielo.php?script=sci_arttext\&pid=S0104-

07072020000100201\&lng=pt\&nrm=iso\&tlng=pt>. Acesso em: 05 nov. 2020.

OMS, Organização Mundial da Saúde. Coronavírus 2020. Disponível em: $<$ https://www.cwho.int/es/emergencies/diseases/novel-coronavirus-2019> acesso em 07 jun.2020.

PETERS, M. Pós-estruturalismo e filosofia da diferença. Trad.: Tomaz Tadeu da Silva. Belo Horizonte: Autêntica, 2000.

PORTAL FIOCRUZ. Disponível em: https://portal.fiocruz.br/noticia/relatorio-atualiza-previsao-dedisseminacao-da-covid-19. Acesso em: 17 de dezembro de 2020. 
PORTAL GEOSAUDEVRP. Disponível em: https://geosaudevrp.org/2020/11/11/evolucao-doscasos-de-covid-19-no-rio-grande-do-sul-dados-publicos-secretaria-estadual-de-saude-rs/\#top. Acesso em: 17 de dezembro de 2020

SANTOS, Milton; Por uma outra globalização - do pensamento único à consciência universal. São Paulo: Record, 2000.

SANTOS, I. A; NASCIMENTO, W. F. As medidas de quarentena na saúde pública: aspectos bioéticos. Revista Bioetikos.2014. Disponível em: <https://saocamilosp.br/assets/artigo/bioethikos/155563/A05.pdf> acesso em: 15 nov, 2020.

SANTA CRUZ DO SUL. Decretos. Disponível em: lhttps://www.santacruz.rs.gov.br/conteudo/decretos Acesso em: 20 novembro, 2020

SECRETARIA DE SAÚDE DO ESTADO DO RIO GRANDE DO SUL. Distanciamento Controlado. Disponível em: https://distanciamentocontrolado.rs.gov.br/. Acesso em: 20 de outubro de 2020.

SATURNINO, Milena Nascimento Guirra et al. Modos de ver e de fazer: saúde, doença e cuidado em unidades familiares de feirantes. Ciência \& Saúde Coletiva [online]. v. 24, n. 5, 2019, pp. 17231732. Disponível em: <https://doi.org/10.1590/1413-81232018245.10602017>. ISSN 1678-4561. https://doi.org/10.1590/1413-81232018245.10602017. [Acessado 17 novembro 2020]

SILVA, L. J. O conceito de espaço na epidemiologia das doenças infecciosas. Caderno de Saúde Pública, Rio de Janeiro, v. 13, n. 4, p. 585-593, out-dez 1997. Disponível em: https://www.scielo.br/scielo.php?script=sci_arttext\&pid=S0102-

311 X1997000400002\&lng=pt\&tlng=pt. Acesso em: 04 set 2020.

SOUZA, Camilo D. Educação, geografia e saúde: geobiopolíticas nos discursos da Organização Mundial da Saúde e a produção da mundialidade pelo controle e prevenção de doenças. Tese (Doutorado em Educação) - Universidade Federal do Rio Grande do Sul, Porto Alegre, 2014. 